\title{
Family Cohesion and the Efficacy of Employees in the Working Environment
}

\author{
Mr.sc Ibrahim Neziri ${ }^{1}$, PhD Candidate \\ Ibadete Kamberi, M.A Candidate
}

\author{
Doi:10.5901/mjss.2016.v7n2p427
}

\begin{abstract}
The purpose of this study is to reveal the relationship between the efficacy of employees in the work environment and the cohesion in their families. Efficacy in the work environment is about the confidence and readiness of a person to successfully perform a certain task, focusing on the belief of a person to organize, operate and manage future situations. Family cohesion is conceived as emotional connection that family members have with each other and an expression of affiliation within the family. In this study, 150 employees of public institutions in Macedonia took part; the average age is 38,93. One-Way Anova was applied to determine the difference of the efficacy scale based on the type of family by cohesion. It showed a valuable difference between the types of disengaged, separated, connected and very connected families in the scale of employees' efficacy in the work environment. The linear regression shows that the employees' efficacy at work can be explained by their cohesion in the family as a predictor. Based on gender, females report higher levels of cohesion while the age and the experience of the employees as moderating variables do not have a statistically significant effect on the relationship of the phenomena.
\end{abstract}

Keywords: efficacy of employees, work place, family cohesion, organization

\section{Introduction}

This study addresses a problem in the field of organizational psychology focusing on the relationship of the employees' efficacy in the work environment and the type of cohesion in the family.

According Bandura (1997), an employee's sense of capability influences his/her perception, motivation, and performance (as cited in Lunenburg, 2011). Based on this, we tend to be more active, to meet certain obligations, then when we perceive and expect to be successful. Self-efficacy has powerful effects on learning, motivation, and performance; because people try to learn and perform only those tasks that they believe they will be able to perform successfully (Bandura, 1982). Family can be broadly defined as the degree of togetherness and emotional bonding that family members have towards one another (Vandeleur et al. 2009), which refers to the integrated relationships between the family members, whether there is warmth, closeness and emotional support among members (as cited in Choi, 2012).

The issue of this study is not treated before in the Republic of Macedonia in the context of studying the relationship between the variables of efficacy and the cohesion in the family. Therefore, the findings of the study are in favor of organizational psychology in the country and beyond, as well as to organizations in their work related to employees.

The main goal of the study is to reveal the relationship between employees' efficacy in the working environment and the types of employees' families by cohesion.

\section{Efficacy in the Working Environment}

Efficiency in the work environment is the basis of operation of each organization, respectively, a primary goal of any leader. "Employees in their various organizations are entrusted to exhibit some work related behaviors in order to execute precisely and well various tasks assigned to them by management", hence according to Mensah (2013), it is therefore important for the management of an organization to know about an employee's efficacy and its impact on his job performance which is related to the quality of work. Self efficacy of employees is the belief in ones capabilities to organize and execute the courses of action required to produce given attainments (Bandura, 1997, p.2). Effects of efficiency can be multiple, so "self-efficacy effects are learned and performed in three ways" (Bandura, 1982); when employees with low levels of self-efficacy tend to set relatively low goals for themselves. On the other hand, an individual with high efficacy is

\footnotetext{
1 State University of Tetovo, e-mail: ibrahim.neziri@unite.edu.mk
} 
likely to set high personal goals. An individual with high self-efficacy is likely to set high personal goals. Research indicates that people not only learn but also perform with their efficacy; therefore efficacy affects learning as well as the efforts people put at work. In general, employees with higher efficacy work hard to learn how to execute their new tasks since they are convinced their efforts will be successful. Employees with lower efficacy put fewer efforts when learning and performing new tasks since they are not sure their effort will lead to success. Efficacy in the working environment mobilizes motivation, cognitive resources and the courses of action necessary to have control over events at work (Wood and Bandura, 1989, p.364). Employees with higher efficacy are convinced they can learn and execute specific tasks. Therefore, they are likely to continue in their efforts even when problems emerge. In an extensive literature review on efficacy, Locke (2002) reached the conclusion that efficacy is a strong determinant of performance at work. Vinokur \& Schul, (2002) declared that people with high efficacy are more likely to overcome unemployment and achieve valuable results through their persistence and reflect inner satisfaction from their work (Yakin \& Erdil, 2012). An empirical study conducted by Luthans \& Peterson, (2002) shows that self-efficacy is a partial moderator between the employee scale and engagement at work. The Department of Management, College of Business Administration, Abu Dhabi University is a study on work efficacy which proves that employee performance has a positive impact on efficacy; it is proved also that organizational behavior of professionals considerably influences on the amount of belief. The complexity of the tasks as well as performance locus is found to moderate the link between self-efficacy and performance at workplace. These two factors play an important role in organizational settings as they have a tendency to deteriorate the link between selfefficacy and performance Jolly Jacob (2013).

\section{Types of Family by Cohesion}

Cohesion in the family is the positive spirit of the welfare of each of its members, Which was identified, at the beginning of 1930's. The cohesion was identified as an important dimension for attempting to understand interactions among family members (Angell, 1936). Green and Werner (1996) suggest that families with high cohesion should include nurturance, warmth, spending time together, consistency and physical intimacy (as cited in Choi, 2012). Researchers as Juffer \& Van ljzendoorn (2005) and Koerner \& Fitzpatrick (2006) have defined family cohesion as an important variable for the functioning of the family. The togetherness, love, values, warmth, loyalty, satisfaction, flexibility in handling conflicts or closeness of a family form the family cohesion (as cited in Uju, 2014). Family cohesion, is associated with many different activities all the time, so Williams (2011) pointed out that: "cohesion is manifested in the practical daily activities that families engage in such as eating meals, watching television, chatting, and expressing faith in one another. It is also demonstrated by the concerted efforts that family members make to show love, respect, kindness, be in harmony, and be satisfied with one another" (as cited in Uju, 2014). When all members of the family, make efforts to successfully implement the goals of the family, then we can say that cohesion in the family is satisfactory, so Spring (1995) noted, it is through cohesion that families face the life events (as cited in Uju, 2014). Thus, the level of family cohesion or of a special equilibrium is achieved between two opposing forces identified by Olson, Sprenkle and Russell (1997) and it is determined by the ways a family faces with the three types of needs of the family members: emotional, social and material. They also concluded that the level of performance appears in the performance of the family activities and to prove that, they developed three indicators on this activity that correspond to the three levels of needs. According to Olson (1993), "Cohesion family is defined as the emotional bonding that family members have toward one another". The Circumplex model of family systems was developed to overcome the gap between research, theory and practice (Olson, Russell and Sprenkle, 1979) (as cited in Olson, 1999). This model is focused on three main dimensions that are important in a variety family theory models. Family cohesion, adaptability and communication are the three dimensions of this model which emerged from 50 most developed concepts on family dynamics. The four levels of family cohesion which are part of this study include: disengaged, separated, connected and very connected families (Olson, 1999). In a disengaged family the members are independent and the emotional bonds are weak. Poor communication takes place between family members. Members of a separated family express a considerable economic independence but emotional bonds are stronger compared to disengaged families. Members of a connected family express less economic independence and emotional bonds are relatively strong. All members of the family have a good communication to one another. In very connected families, there is an economic independence and emotional bonds are very strong and communication is high in one direction of cohesion (Olsen, Sprenkle \& Russell 1979) (as cited in Miller\&Clyde). Individuals who live in families with high family cohesion constitute warmth, autonomy and their members have interpersonal skills and stronger emotional bond within the family (Feldman et al. 1998). Except this, the relationship with family members is a very important experience for an individual's development in later social interaction and interpersonal skills (Green \& Werner 1996). 


\section{Methodology}

\subsection{Sample and implementation}

Based on other similar studies and efforts to determine the scale of the relationship between certain variables using statistical data, quantitative approach to measuring variables with relevant instruments, the objectivity of the study, the number of subjects involved in the study, this is a non-experimental research with correlational design. The population of this study consists of public institution employees in the city of Tetova, Republic of Macedonia. The sample is selected based on the random group method. The total number of participants is 150 employees from six institutions in the city of Tetova and its surroundings such as: the Municipality of Tetova and Zhelina, the State University of Tetova, The Public Municipal Enterprise, Healthcare Fund and Social Office/Entity. According to the control variables in the questionnaire, the age of the subjects is included; from minimal age of 20 years to the maximum of 60 years, with an average of 38.93 years. Based on gender, 98 are male and 52 are female; the average work experience is 9.69 years. The other measured demographic characteristics will not be shown since they are not part of this study's goal. The employees' participation in the chosen organizations was on voluntary basis and an absolute anonymity was guaranteed by the author. Participants were not informed about the study's variables at the beginning of filling out the instruments and have received clear instructions about filling out the questionnaire, while at the end, they have been informed about the goal of the study in order to verify their participation in the study. This study was accomplished from November 2014 to January 2015. The study was conducted by the researcher in cooperation with other persons, which have been trained related to the form of applying the questionnaire but they have not known the problem and the goal of the research. As a result of participation refusal, only three subjects were excluded from further measurements and were declared as null. The appropriate period of the survey time during the working hours and holidays was respected.

\section{Instruments}

To measure efficacy in the working environment in accordance to the essential theories of this study S-WSES- Work SelfEfficacy Scale (Avallone et al 2007) was applied. The scale of efficacy at work S-WSES includes 22 statements related to the evaluation of perceptions on specific work fields such as: the skill to manage interpersonal relationships (with colleagues and the supervisor) working with colleagues with different characteristics and experiences, executing efficiently in the working context, learning new working methods, respecting schedules and working terms and achieving the goals set. Based on the Alpha Cronbach coefficient, the test reliability S-WSES results high ( $=0.85$ ) (Avallone et al. 2007). This scale was applied in the Republic of Macedonia by Drita Ajro (2012) with employees of private organizations and results in high reliability ( $=0.84)$; in the actual study, the internal inter-correlation of the instrument is high $(=0.89)$. The evaluation of 22 statements with 1 (almost never) to 5 (almost always), has shown the efficacy at the working environment, respectively the amount of the highest scores has shown greater presence of efficacy.

The family cohesion or the types of families by cohesion are measured through FACES III by David H. Oslon \& July Watson Tiesel, Joyce Portner and Yoav Lavee, April 1991. The family cohesion is measured by 10 questions evaluated by 1 (almost never) and 5 (almost always). The highest amount of scores by participants determines the highest level of cohesion in the family, respectively the family type by cohesion in certain intervals as follows: 10-34 scores determines disengaged families, 35-40 separated families, 41-45 connected families and 46-50 very connected families. FACES III has sufficient internal reliability $(=0.68)$ as well as high Test-retest reliability $(r=0.80)$. In our study, this instrument achieves satisfactory reliability $(=0,59)$.

\section{Results}

Based on the gathered results on the scale of work efficacy, this variable results with an average $(M=94,03, S D=10,77)$, which exceeds the average value of the scale and shows a relatively high level of efficacy of employees in the working environment. It ranges between the minimal value 65 and maximal 110 . The cohesion in family as an accumulated variable from the overall values from 10 questions results with an average $(M=38,29 ; S D=6,46)$, referring to the achieved minimal value 22 and maximal 49. The achieved average shows a level over the moderate average of employees family cohesion (Table 1). 
Table 1. Descriptive statistics of family cohesion and efficacy at work

\begin{tabular}{|c|c|c|c|c|c|c|}
\hline & $\mathrm{N}$ & Minimum & Maximum & & lean & Std. Deviation \\
\hline & Statistic & Statistic & Statistic & Statistic & Std. Error & Statistic \\
\hline Cohesion & 150 & 22.00 & 49.00 & 38.28 & .52 & 6.46 \\
\hline Efficacy at work & 150 & 65 & 110 & 94.03 & .87 & 10.77 \\
\hline Valid N (listwise) & 150 & & & & & \\
\hline
\end{tabular}

According to type of family cohesion presented in Table 2, 27 participants or $18.12 \%$ were classified in disengaged family, 43 in separated family or $28.86 \%, 59$ in connected families or $39.60 \%$ and 20 of subjects in very connected families or $13.42 \%$. Based on the results of One-Way Anova in Table 2, to find the difference between the scale of employees efficacy in the working environment based on family cohesion, a higher efficacy at work is shown with employees of families with high cohesion or very connected $(M=100.80, S D=5.99)$, secondly of connected families ( $M$ $=97.37, S D=8.82)$, then the separated families $(M=93.32 ; S D=9.97)$, while the lowest level which differs from other types of families appears with disengaged families $(M=82,85 ; S D=9,11)$. Based on Levin's test about the homogeneity of the variance $F(3)=2,28 ; p>0.05$, the value of averages comparison according to Anova about the scale of employee efficacy and family cohesion, it results statistically acceptable $F(3,145)=20,81 ; p<0.01$, according to which, there are differences on the employees efficacy at work among the four types of cohesion in the disengaged, separated, connected and very connected families. The statistics of post hoc Sheffe shows a statistically significant difference $(p<0.01)$ between the disengaged families and all other types of families by cohesion, i.e. the separated, connected and very connected families. The connected and very connected families result in an insignificant difference of the variance among them.

Table 2. The average of efficacy by the type of family cohesion

\begin{tabular}{lccc}
\hline \hline Cohesion & Number of employees & Average of efficacy & Standard deviaton \\
\hline Disengaged & 27 & 82.85 & 9.11 \\
Separated & 43 & 93.32 & 9.97 \\
Connected & 59 & 97.37 & 8.82 \\
Very connected & 20 & 100.80 & 5.99 \\
Total & 150 & 94.03 & 10.56 \\
\hline \hline
\end{tabular}

$F(3,145)=20,8 \overline{\overline{81 ;} p<0.01}$

Graphically, the difference of scores of the value of efficacy by type of family is shown in Graph 1.

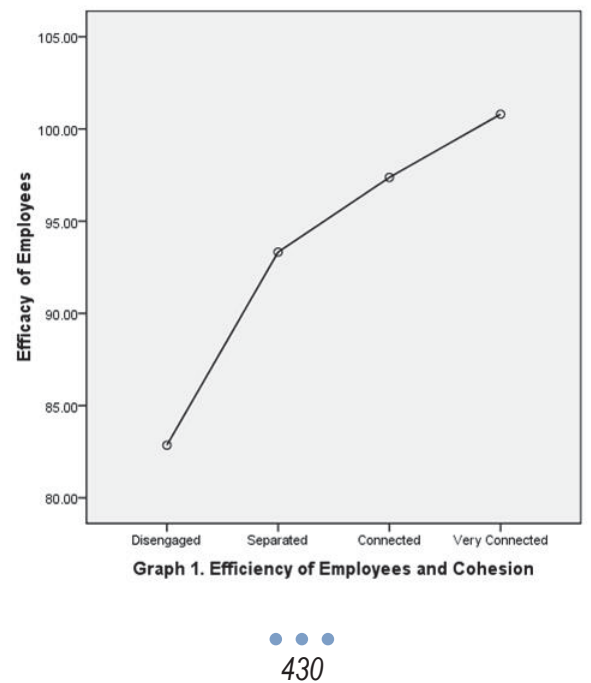


To see the interrelation between employees efficacy at work and family cohesion we used Pearson's Coefficient (table 3), which shows valuable relation with positive direction $(r=0,54 ; p<0.01)$, where the positive relation refers to the increase of employees efficacy at work with the increase of family cohesion. The Spearman's correlation $(r=0,50 ; p<0.01)$ shows the positive relation of family types by cohesion and employees efficacy at work. The optimal statistically significant coefficient shows that employees families which have the tendency to be emotionally more bonded among one another have the tendency of increasing the respective employee's efficacy at work.

Table 3. Correlation between efficacy at work, family cohesion and types if families by cohesion

\begin{tabular}{llll}
\hline \hline & & Cohesion & Type of family \\
\hline & Pearson Correlation & $.540^{* *}$ & \\
& Sig. (2-tailed) & .000 & \\
\multirow{4}{*}{ Employees efficacy } & 150 & \\
\cline { 2 - 4 } & $\mathrm{N}$ & & $.500^{* *}$ \\
& Spearman's rho & .000 \\
& Sig. (2-tailed) & 150 \\
\hline \hline${ }^{* *}$. Correlation is significant at the 0.01 level (2-tailed). &
\end{tabular}

The analysis of linear regression reports that family cohesion explains the employees efficacy at work with $29 \%$ of the variance $\left.R^{2}=.29, F(1,148)=60,87, p<.01\right)$. Family cohesion predicts the employees efficacy at work in a considerable scale $(\beta=.54, p<.001)$.

Table 4. Regression analysis for cohesion in family predicting efficacy of employers

\begin{tabular}{|c|c|c|c|c|c|}
\hline \multirow{2}{*}{ Model } & \multicolumn{2}{|c|}{ Unstandardized Coefficients } & \multirow{2}{*}{$\frac{\text { Standardized Coefficients }}{\text { Beta }}$} & \multirow{2}{*}{$t$} & \\
\hline & B & Std. Error & & & \\
\hline 1 (Constant) & 60.219 & 4.409 & & 13.659 & .000 \\
\hline Cohesion in family & .886 & .114 & .540 & 7.802 & .000 \\
\hline
\end{tabular}

a. Dependent Variable: Efficacy at work $\left(\mathrm{R}^{2}=.29\right.$, $F(1,148)=60,87, p<.01)$

The analysis of t-test was used for possible differences between males and females in the averages of efficacy and cohesion in families. This comparative analysis results in valuable difference between male and female employees in the degree of cohesion in the family $t(2)=-2.628, p<0.01$, where women report more cohesion in their families $(M=40.15$; $S D=4.92)$ than men $(M=37.29, S D=6.96)$. On the scale of efficacy there is no valid difference among genders $(p=$ n.s).

Factors used as moderating variables in the type of family cohesion are the age and experience of the employees participating in the study. The control of the effect of age and experience variable was tested with the analysis of covariance (Ancova), which shows that the employees efficacy by type of family cohesion, has no effect under the control of age and experience of employees $F(19.69)=0.58,1.68, p=0.44,0.19$ (Table 4). Age and experience at work has no valuable relationship with efficacy at work and employees' family cohesion.

Table 5. Ancova for the effect of Age and Work experience in the difference of cohesion and efficacy at work

Dependent Variable: Efficacy at work

\begin{tabular}{lccccc}
\hline \hline Source & Type III Sum of Squares & df & Mean Square & F & Sig. \\
\hline Corrected Model & $5110.750 \mathrm{a}$ & 5 & 1022.150 & 12.819 & .000 \\
Intercept & 61515.842 & 1 & 61515.842 & 771.505 & .000
\end{tabular}




\begin{tabular}{lccccc} 
Age & 46.941 & 1 & 46.941 & .589 & .444 \\
Experience & 134.510 & 1 & 134.510 & 1.687 & .196 \\
Cohesion & 4710.664 & 3 & 1570.221 & 19.693 & .000 \\
Error & 11402.082 & 143 & 79.735 & & \\
Total & 1334017.000 & 149 & & & \\
Corrected Total & 16512.832 & 148 & & & \\
\hline \hline
\end{tabular}

a. R Squared $=.310$ (Adjusted R Squared $=.285$ )

\section{Conclusion}

The findings of this study, referring to the main goal, found that there was a statistically significant positive relationship between the scale of employees' efficacy at work and family cohesion. Based on four types of cohesion in the family, the results showed that the difference of disengaged, separated, connected and very connected families on the employees efficacy was statistically acceptable, where employees of connected and very connected families showed more efficacy at work in better mobilization in recognition resources and handling courses required for events at work (Bandura, 1989). Employees of disengaged families, which is explained by low level of emotional bonding between family members, showed a lower level of efficacy at work, who had significant difference compared to all types of other families by cohesion, while even the employees of separated families which in emotional bonds include the higher level than that the separated ones, reported significant differences with other families with the highest cohesion in the scale of efficacy.

In general the increase of efficacy at work was at positive linear relationship with the increase of family cohesion. Such finding is supported by a similar study conducted earlier which proves that people who have higher efficacy experience have better communication in the family and are less inclined to dispute (Albert Bandura, Gian Vittorio cymbal; Conetta Pastorelli \& Camillo Regalia, Eugenia Scabini, 2005).

In the present study, employees who declared they come from more cohesive families, showed a more emphasized level of efficacy at work, related to specific fields of work, the skill to manage interpersonal relationships with colleagues and the supervisor, working with colleagues, to changed and effectively implement different situations at work, the tendency to enrich new working methods (Avallone et al. 2007). Relationships between family members create special experiences on personal development and better social interaction (Green \& Werner 1996), thus the research shows that the individual who grows up in a cohesive family environment with authoritarian parents, convenient autonomy and control, is relatively competent at work, psychologically healthy, has good interpersonal skills and high self esteem. Individuals, who live in families with high family cohesion, constitute warmth, autonomy and their members have interpersonal skills and stronger emotional bonds within the family (Feldman et al. 1998). Based on the importance of family cohesion according to the theories and research mentioned in the present study, we found that family cohesion predicts efficacy in the working environment in a satisfactory level.

Another issue this study addressed is the gender difference between men and women related to family cohesion, where men show a lower level of family cohesion than women, and on efficacy at work, there is no statistically significant difference. Another study conducted in Utah in the United States comes to the conclusion that women are more responsible and show a higher level of family cohesion. Family cohesion differs from men to women. For women, work and its characteristics influence family cohesion, while in cultural aspect men have shown that are more likely to commit to work than to family (Daphne Pedersen Stevens, Gary Kiger, Pamela J. Riley, 2006). On the other hand the absence of gender differences in efficacy at work confirms that both genders are equally skilled to perform a particular job. This is also confirmed by a study conducted in Kentucky in the United States stating that gender in itself does not affect the efficacy at work or entrepreneurship (Stephen L. Mueller \& Mary Conway Dato-on, 2007). Age and work experience of the subjects had no effect on the relationship of efficacy and family cohesion.

Due to the lack of similar studies in the context set forth by the actual study, the variables of the study and findings comparisons are limited. However, the findings of the study are important for the organizations and organizational psychology; giving information about different factors which interact in the working environment. Higher efficacy is shown by employees who come from families of high scale of cohesion, stronger emotional bond among one another.

\section{Limitations}

Although in terms of control factors this study indicates good internal validity, different threats limit it in various forms. In 
the first instance, inclusion of only a few public companies and not private ones reduce the size of generalization of the study findings. The difference of the work nature and occupations between institutions threatens the findings of the study, although in the aspect of statistical results this difference has no statistically valid effect. The influence of personal factors during the application of the study and work environment factors during data collection have had an effect on the findings and individual completion of measurements. Although the conditions and conducting of the survey are managed by ensuring complete anonymity, however, it remains that in the future even better conditions for the inclusion of subjects in the survey should be planned. Another limitation of the study is the inclusion of only Albanian ethnic group subjects and the number of subjects. In future, this study can surely be expanded in other cities as well, and private organizations can be included, at the same time including more subjects in the sample of public organizations.

\section{References}

Angell R., (1936). "The family encounters the depression", New York, Charles Scribner's Sons

Avallone, F., Pepe, S. \& Porcelli, R. (2007). "Perceived self-efficacy in job-research: scales of measurement". In Isfol, Bisogni, values and self-efficacy in the choice of work. Roma: ISFOL, 133-142, Cited in Silvia, J., Maria, L., Avalone, F., Vecchione, M. (2010). "Work Self-Efficacy Scale and Search for Work Self-Efficacy Scale: A Validation Study in Spanish and Italian Cultural Contexts", Revista de Psicología del Trabajo y de las Organizaciones 26 (3), 201-210.

Bandura, A. (1977). " Social learning theory". Englewood Cliffs, NJ: Prentice Hall. International Journal of Management, Business and Administration, Volume 14, number 1, 2011. Cited in Lunenburg, C. (2011). "Self-Efficacy in the Workplace: Implications for Motivation and Performance", International Journal Of Management, Business, And Administration 14 (1). Available at: http://www.nationalforum.com/Electronic\%20Journal\%20Volumes/Lunenburg,\%20Fred\%20C.\%20SelfEfficacy\%20in\%20the\%20Workplace\%20IJMBA\%20V14\%20N1\%202011.pdf, (November 5, 2014).

Bandura, A. (1982). " Self-Efficacy mechanism in human agency", American Psychologist, 37, 122-147. International Journal of Management, Business and Administration, Volume 14, number 1, 2011.

Bandura, A., Wood, R. (1989). Effect of perceived controllability and performance standards on self-regulation of complex decision making. Journal of Personality and Social Psychology, 56, 364

Daphne Pedersen Stevens, Gary Kiger, Pamela J. Riley, (2006). "His, hers, or ours? Work - to family spillover, crossover, and family cohesion". The Social Science Journal 43 (2006) 425-436 Available: http://naulibrary.org/dglibrary/admin/book_directory/ Psycology/5573.pdf (April 2, 2015)

Drita .A (2012). "Self-efficacy in the work environment and the level of payment for the work done", Punim diplome në katedrën e Psikologjisë, Universiteti Shtetëror i Tetovës: Tetovë

Feldman, S. S., Gowen, L.K., and Fisher, L., 1998. " Feldman, S. S., Gowen, L.K., and Fisher, L., 1998. "Family relationship and Gender as Predictors of Romance Intimacy in Young Adults", Journal of research on Adolescence, 8 (2), 263-186. Discovery-SS Sudent E-Journal, Vol, 1, 2012, 91-109

Gian Vittorio Caprara \& Concetta Pastorelli \& Camillio Regalia \& Eugenia Scabini, Albert Bandura, (2005). "Impact of adolescent's Filial Self-Efficacy on Quality of Family Functioning an Satisfaction", Journal of research on adolescene, 15 (1),71-97 Available at: http://www.uky.edu/ eushe2/Bandura/Bandura2005JRA.pdf (April 2, 2015).

Green, R. J., and Werner, P.D., (1996). "Intrusiveness and closeness-care giving: Rethinking the concept of family enmeshment". Family Process, 35, 115-136, . Cited in Choi, K (2012). "The relationship between Family Cohesion and Intimacy in Dating Relationship: A Study Based on Attachment and Exchange Theories", Discovery-SS Student E-Journal (1), 91-109, Available: http://ssweb.cityu.edu.hk/download/RS/E-Journal/journal5.pdf (December 3, 2014).

Jolly Jacob (2013) . "Impact of Self Efficacy on Motivation and Performance of Employees", Abu Dhabi. International Journal of Business and Management, 8 (14), 80-88. doi:10.5539/jijbm.v8n14p80

Juffer F., \& Van lizendoorn, M. H. (2005). "Behaviour problems and mental health referrals of international adoptees: A meta-analysis". Journal of the American Medical Association, 293, 2501-251. Cited in Uju, P. (2014). "Children's view on Family Cohesion in Families with biological and adopted Children in Anambra State", Research Journal in Organizational Psychology \& Educational Studies 3(5) 330-335, Available at: http://rjopes.emergingresource.org/articles/CHILDRENS\%20VIEW\%200N\%20FAMILY.pdf (April 3, 2015).

Koerner, A. F, \& Fitzpatrick, M. A. (2006). "Family communication patterns theory: A social cognitive approach", New York, Thousand Oaks, CA Available: http://rjopes.emergingresource.org/articles/CHILDRENS\%20VIEW\%200N\%20FAMILY.pdf (April 3, 2015)

Locke, E. A., \& Latham, G. P. (2002). "Building a practically useful theory of goal setting and task motivation", A 35-year odyssey. American Psychologist, 57(9), 707-717

Mensah, O. A (2013). "The Influence of Employees' Self-Efficacy on Their Quality of Work Life: The Case of Cape Coast, Ghana", International Journal of Business and Social Science Vol. 4 No. 2; February 2013195

Olson D. H Sprenkle D. H. \& Russell C.S. (1979)."Circumplex Model of Murital and Family System: Cohesion and Adaptability Dimensions, Family Types nd Clinical Applications". Family Process 18, pp 3-27. Cited in Olson, D. (1999). "Circumplex Model of Marital \& Family Systems", Journal of Family Therapy, Available at: http://www.uwagec.org/eruralfamilies/ERFLibrary/ Readings/CircumplexModelOfMaritalAndFamilySystems.pdf (April 4, 2015).

Olson, D. H. (1993). Circumplex Model of marital and family systems: Assessing family functioning. In Walsh, F. (Ed.), Normal family 
processes, (2nd ed.) (pp.104-137). New York: Guilford Press

Spring, B. (1995). Understanding Adoption in Zetterson, R. (Ed) Parents resource bible:The living bible, (p, 1150). Colorado:Tynadale House Publishers. Research Journal in Organizational Psychology \& Educational Studies 3 (5) 330-335, Anambra. Available: http://rjopes.emergingresource.org/articles/CHILDRENS\%20VIEW\%200N\%20FAMILY.pdf (April 3, 2015)

Stephen L. Mueller \& Mary Conway Dato-on, (2007). "Gender Role Orientation as a Determinant of Entrepreneurial". Journal of Developmental Entrepreneurship. Available at: http://cmapsconverted.ihmc.us/rid=1225644184531_1897371111_6335/stephenmueller-gender-role-orientation-self-efficacy.pdf (April 4, 2015)

Vandeleur, C. L., Jeanpretre, N., Perrez, M., and Schoebi, D., (2009). "Cohesion, Satisfaction with Family Bonds, and Emotional WellBeing in Families with Adolescents. Journal of Marriage and Family, 71 (5), 1205-1219. Cited in Choi, K (2012). "The relationship between Family Cohesion and Intimacy in Dating Relationship: A Study Based on Attachment and Exchange Theories", Discovery - SS Student E-Journal (1), 91-109, Available: http://ssweb.cityu.edu.hk/download/RS/E-Journal/journal5.pdf (December 3, 2014).

Williams, F. (2011). "Comparing adolescents in diverging family structures: Investigating whether adoptees are more prone to problems than their noon-adopted peers". Research Journal in Organizational Psychology \& Educational studies 3 (5) 330-335 Available: http://rjopes.emergingresource.org/articles/CHILDRENS\%20VIEW\%200N\%20FAMILY.pdf (February 15, 2015) 